\title{
BIBECHANA
}

ISSN 2091-0762 (Print), 2382-5340 (Online)

Journal homepage: http://nepjol.info/index.php/BIBECHANA

Publisher: Department of Physics, Mahendra Morang A.M. Campus, TU, Biratnagar, Nepal

\section{Pyrolyzed human hair: a review on synthesis, characterization and applications}

\author{
Tika Ram Bhandari ${ }^{1,2}$, Bidit Lamsal ${ }^{2,3}$, Rameshwar Adhikari ${ }^{2,3 *}$ \\ ${ }^{1}$ Tribhuvan University, Central Department of Physics, Kathmandu, Nepal \\ ${ }^{2}$ Tribhuvan University, Research Center for Applied Science and Technology, Kathmandu, Nepal \\ ${ }^{3}$ Tribhuvan University, Central Department of Chemistry, Kathmandu, Nepal \\ *Email: ram.adhikari.tu@gmail.com,r_adhikari@recast.edu.np
}

Article Information:

Received: June 23, 2020

Accepted: September 3, 2020

Keywords:

Hair, Pyrolysis, Biomedicine

Sensors

Microscopy Spectroscopy

\begin{abstract}
Human hair, a common biowaste, can be pyrolyzed to prepare many kinds of functional materials. Pyrolyzed hair has been used as in various forms of traditional medicine, sensor, ink and electrolytes. This review highlights the major structural characteristics of human hair and its pyrolyzed form. It also addresses the characterization techniques used for the structure elucidation of pyrolyzed human hair as well as its potential applications..
\end{abstract}

DOI: https://doi.org/10.3126/bibechana.v18i1.29601

This work is licensed under the Creative Commons CC BY-NC License. https://creativecommons.org/licenses/by-nc/4.0/

\section{Introduction}

Hair is the collection of the pigmented filaments of keratin growing from the skin of the humans and mammals. It forms a covering for a part of the head and/or for other parts or the whole body. Each filament is divided into three major compartments: cuticle, cortex and medulla. Depending upon types of origin, diameter of hair varies from $50 \mu \mathrm{m}$ to $100 \mu \mathrm{m}$. Hair filament is composed of keratinized dead cells [1] and has alpha keratin, beta keratin and matrix proteins and low sulphur. Generally, the hair fiber contains $50-60 \% \quad \alpha$-keratins, $20-30 \%$ matrix proteins and different pigments like melanin, water (up to 30\%), lipids (structural and free), and trace elements [2]. Toughness of hair is due to the accumulation of the $\alpha$-keratin which forms a micro fibrous structure called as intermediate filaments (KIFs). Helical protein with 20 to 50 amino acids is found in human hair which includes amino acids such as; Glycine, Alanine, Valine, Isoleucine, Leucine, Phenylalanine, Tyrosine, Lysine, Arginine, Ornithine, Histidine, Citruline, Glutamic acid, Threonine, Serine, Cystine, Methionine, Cystiene, Cysteic acid, Proline, and Tryptophan. However, aspartic acid and glutamic acid exist as the primary amides and free acids respectively in human hair. Among them, Cystine is the major form of amino acid. A very strong crosslinked sulphide bond, called disulphide linkage, is found between two Cystine amino acid groups in two neighboring helical chains. The 
matrix protein which impart such disulphide linkage and glue the two chains together are termed as keratin associated proteins (KAPs) [3].

Morphology of human hair of different people of different origins was studied with the help of scanning electron microscopy (SEM). The SEM investigations on three different kinds of hairs are presented in figure 1. SEM micrographs reveal that, people of different origins have dissimilar hair structures. The observed variations in the structure are associated with keratin genes and keratin associated proteins (KAPs). There are altogether 17 human hair keratin genes and more than 85 KAPs genes have been recognized [4].

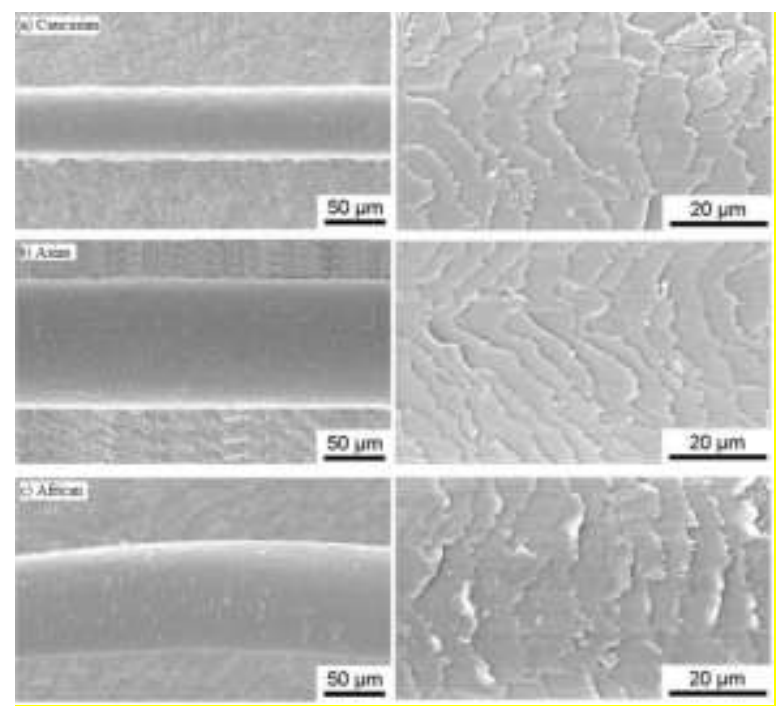

Fig. 1: Lower (left) and higher (right) magnifications SEM images of Caucasian (a), Asian (b), and African (c) hair [5]

SEM images (figure 1) at lower magnification show that Caucasian hair has much smaller $(50 \mu \mathrm{m})$ diameter than the African $(80 \mu \mathrm{m})$ and the Asian $(100 \mu \mathrm{m})$ hairs. Highly magnified micrographs of the hair at the scalp region reveal that the cuticle of each type of hair has scaled laminar structure. However, the Asian hair has more folded structure than the others.

Similarly, SEM on a single hair filament of Caucasian was used to study the morphological variation at three different parts of human hair by Wei G. et al [5]. SEM images of the hair at low resolution show the diameter of hair at scalp and middle region is almost same but slightly smaller diameter is observed towards the tip region. SEM images at higher magnification further reveal that cuticle is fully developed and organized towards the bottom region of the hair.

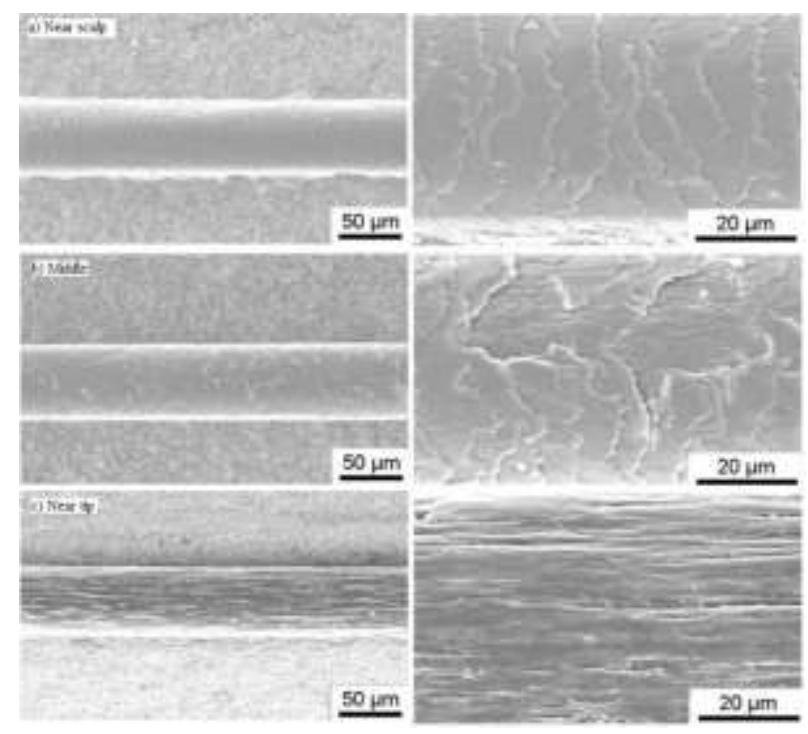

Fig. 2: SEM images of single strand of the human hair near scalp (a), at the middle (b) and near the tip (c) at different magnifications showing the cuticle is gradually lost from bottom to the tip region [5]

Cuticle deposition gradually decreases from middle to tip region. It was reported that the tip region of the human hair has no outer covering cuticle. Cuticle content on different parts of hair depends upon the mechanical damage faced by hair such as friction and combing. Therefore, it can be deduced that the tip region has no cuticle due to high mechanical stress, middle region has intermediate and bottom or near scalp region has no any mechanical damage [5].

Additionally, chemical composition of hair makes it very slow degradable. Deposition of the chemicals such as like cystine, cysteic acid, proline, serine, isoleucine, leucine, methionine, theorine, throsine, phenylalanine and arginine, is more in cuticle than other part of the hair [6] which reduces 
the degradability of hair. Therefore, human hair is generally considered as useless waste in the society. This waste produces a foul smell and burning of hair in the open surrounding produces an unpleasant odor along with harmful gases such as ammonia, carbonyl sulphides, hydrogen sulphides, sulphur dioxide, phenols, nitriles, pyrroles and pyridines [7, 8]. Nowadays, it has become challenge to control this biological waste. Alternately, hair can be used for various purposes in modified and unmodified forms. Systematic reduction and reuse of this waste may improve our periphery as well as contribute our economy. Hair fibers are made up of strong filaments which can be used as scaffold for tissue engineering application because of human origin and cytocompatibility [9]. Many studies on human hair have demonstrated that keratin can be used to develop the biomaterials for biomedical applications, for making keratin films, keratins sponges, and scaffolds and also used in the tissue engineering and regenerative medicine. Due to the high sulphur content, ability of selfassembly and intrinsic cellular identification, keratinized biomaterials has several distinct merits over pre-existing biomolecules $[2,10]$.

In past days, researches were conducted to extract the keratin at wet condition and many research papers, as well as patents have been published. However, there is only handful of publications on the study of pyrolyzed human hair. First use of the pyrolyzed human hair was documented by a Chinese herbalist Li Shi-Zhen in his book Ben Cao Gang in $16^{\text {th }}$ century [11]. The main emphasis of this review is to collect information from previous work in one paper and to find out some gaps on it for possible future research.

\section{Pyrolysis of organic matter and hair}

Dense efforts have been conducted for minimizing the problem of the municipal waste like hair fiber. Hair fiber as composite material, pest controlling agent and some biomedical applications has been minimizing the risk due to the hair fiber [8]. Another way to control this organic waste is pyrolysis. It is the process to change any organic matter in the absence of oxygen to obtain an array of solid, liquid and gas products. Pyrolysis is widely used for production of a wide range of solvents, chemicals, fuels and other products from biomass. Pyrolysis can be done into three ways; low temperature $\left(<550{ }^{\circ} \mathrm{C}\right)$, moderate temperature $\left(550^{\circ} \mathrm{C}\right.$ to $\left.800^{\circ} \mathrm{C}\right)$ and high temperature $\left(>800^{\circ} \mathrm{C}\right)$. Slow conventional pyrolysis includes irreversible thermal decomposition of the organic matter for the production of biomass as well as charcoal. Solid after the pyrolysis contain char, ash and unchanged biomass. Heating rates, temperature and quenching phenomenon determine the nature of product like fraction occupied by the organic ashes in char after pyrolysis. When the char has appropriate pore structure and surface area, it can be used in the preparation of active carbon [12,13,14]. The liquid produced from pyrolysis can be used as fuel and raw materials for synthesis of fine chemicals, fertilizers, and adhesives etc. [15, 16].

Pyrolysis of the human hair at moderate temperature yields a black, shiny solid product. Pyrolyzed human hair has several significant applications. Pyrolysis transforms the nondegradable hair as a degradable one. The char after pyrolysis of human hair can be used as medicine [8]. It contains pore structure and has high surface area so that they are highly applicable for the electrode in the supercapacitors. Study carried on it reveals, the pyrolyzed hair contain heteroatom doped carbon and heteroatom doped carbon has higher performance on the oxygen redox reaction in electrochemical catalytic system. Few studies were carried on the pyrolyzed human hair in order to investigate its conductive properties, capacitive properties and production of quantum dots $[2,17$, 18]. Details about the past studies are involved in the application part of this paper.

\section{Applications of pyrolyzed human hair}

Some important application of the pyrolyzed human hair includes; medicine, electrodes, art and paintings, sensor and others are described below: 


\section{Biomedicine}

In ancient period, pyrolyzed hair was taken as an important medicine. The first use of the pyrolyzed hair for medical application was mentioned by the Chinese herbalist by the name of 'Xue Yu Tan'. He described more than 11,000 therapeutic medicines. Carbonized hair, which is referred to as Crinis Carbonisatus, is one of them, which was used to increase blood clotting and wound healing $[2,11]$. Ash of organic matter is also reported as an important natural biomedicine. Ash of wood chip, buffalo dung has been used for wound healing [19] and the smoke from the pyrolysis of the keratinized materials like hair, feather have been reported for anesthesia of the honey bees. Hydrogen sulphide produced during pyrolysis was found as a main agent for anesthesia of honey bees on that study [20]. Rural communities of South Asian countries still use pyrolyzed hair for long term recovery and fast pain relief on the open wound [21]. But the systematic study of the pyrolyzed human hair as biomedicine has not been reported yet. Moreover, the chemical agents present in pyrolyzed human hair and responsible for the blood clotting and wound healing still remain a mystery.

\section{Art and painting}

In 2014, The Straits Times published an article about the use of human hair as art and its carbonized material as ink. Chinese artist $\mathrm{Gu}$ Wenda worked on his different formulations for painting in which he used paper made from green tea and the ink made of the carbonized hair [22]. Hence, use of pyrolyzed hair in production of ink and use of the hair as art provides a new path for reducing waste through traditional method and also innovation on ink making

\section{Quantum dots for sensor}

Quantum dots are the particle which is form due to the excessive size reduction; so that the three dimension structure reaches the nanometer range [23]. The production cost of the nanoparticles is generally high. However, the recent research shows a highly fluorescent carbon quantum dots can be obtained from the thermal treatment of the hair. Black solid product obtained after thermal treatment of the human hair at $200{ }^{\circ} \mathrm{C}$ for about 24 hours which after dissolution and centrifugation change into carbon quantum dots solution. Direct thermal treatment yield more carbon quantum dots (CQDs) than hydrothermal treatment of hair. These carbon quantum dots are highly useful in sensory of various metal ions like $\mathrm{Hg}^{2+}, \mathrm{Ag}^{+}, \mathrm{Cu}^{2+}$ and $\mathrm{Fe}^{3+}$ and also very useful for testing of water purification. Guo et. al reported that CQDs can detect the minimum level up to $10 \mathrm{nM}$ of $\mathrm{Hg}^{2+}$ as shown in figure $3(\mathrm{~B})[24,25,26]$.
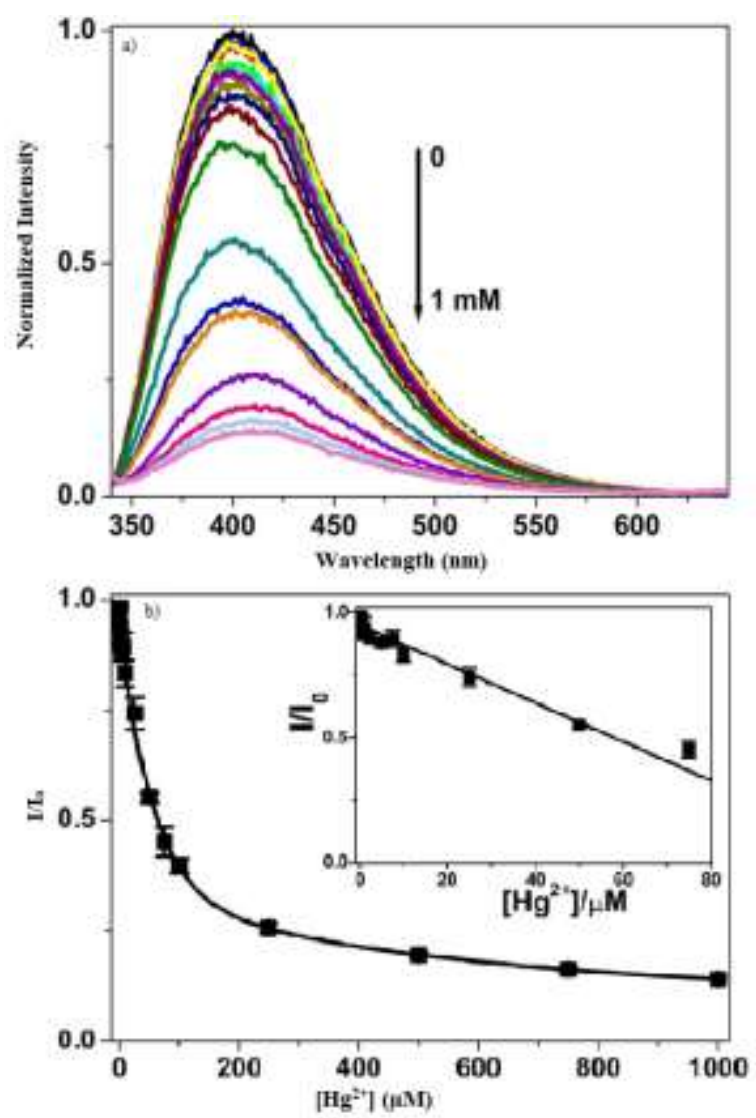

Fig. 3: Fluorescence emission spectra of CQDs showing peak at $415 \mathrm{~nm}$ which decreases with the concentration of $\mathrm{Hg}^{2+}$ (a); and relative intensity plot $\mathrm{I} / \mathrm{I}_{0}$ versus concentration of $\mathrm{Hg}^{2+}$ (b) [24]

\section{Energy application}

Fuel cells are the energy storing devices. They provide clean energy. In fuel cell, Pt and Pt based 
electrocatalysts are used to accelerate the oxygen reduction reaction (ORR). High cost, low long term stability of the Pt and Pt based electrocatalysts interfere for the commercialization of fuel cells [27, 28, 29]. However, it has been found that heteroatom doped carbons from the pyrolyzed hair intensify the ORR reaction than $\mathrm{Pt}$ and $\mathrm{Pt}$ based catalysts. For ORR performance, peroxide species $\left(\mathrm{HO}_{2}{ }^{-}\right)$yield and electron-transfer number during the phenomenon was monitored. Sample with temperature $900{ }^{\circ} \mathrm{C}$ showed low yield of $\mathrm{HO}_{2}{ }^{-}$and high electron transfer number as compared to other sample $\left(800{ }^{\circ} \mathrm{C}, 1000{ }^{\circ} \mathrm{C}, 1100{ }^{\circ} \mathrm{C}\right)$. Further to confirmed sample as better electrocatalyst for ORR methanol tolerance and stability test was performed on heteroatom doped carbon of $900{ }^{\circ} \mathrm{C}$, the obtained result was far good as compared to $\mathrm{Pt} / \mathrm{C}$ catalysts at constant potential of $-0.3 \mathrm{~V}$ for $14 \mathrm{~h}$ in an $\mathrm{O}_{2}$ - saturated $0.1 \mathrm{M} \mathrm{KOH}$ solution. Heteroatom doped carbon obtained from hair char have nitrogen and sulphur in carbon structure and also has graphite like stack form. This structure of carbon with hetero atoms increases the activity of the oxygen in oxygen reduction reaction. Resistance of the pyrolyzed char was found very low and decrease with increase in temperature.

Researchers have reported the development of a superior and stable metal free catalyst having excellent electrochemical properties from pyrolyzed hair sample [18]. It may provide alternative catalysts for fuel cells in replace of $\mathrm{Pt}$ and Pt based catalysts.

Moreover, it is also highly applicable in supercapacitors. Capacitors are the electric devices that are used to store the energy. Supercapacitors are fast-charging energy storage devices having intermediate specific energy. They are designed to solve the gap between batteries and capacitors. Super capacitor has high capacitance than congenital capacitors which highly depend upon the surface area of the electrode used [30]. The capacitance value of carbonized human hair in argon atmosphere at $800{ }^{\circ} \mathrm{C}$ was found $340 \mathrm{Fg}^{-1}$ at a current density of $1 \mathrm{Ag}^{-1}$ in $6 \mathrm{M} \mathrm{KOH}$ and also good stability over 20000 cycles while evaluating electrochemical performance in a fully assembled two electrode cell with the $1 \mathrm{M} \mathrm{LiPF}_{6}$ EC/DEC electrolyte [17]. The high capacitance is the result of hydrophilicity and polarity of electrode which is induced due to doping of heteroatoms and porous structure in the carbon materials. It was demonstrated that the pyrolysis transfer human hair into highly porous, conductive heteroatom doped carbon char having high surface area. Thus, electrode from the carbonized human hair has high energy and power density which can be a good candidate for energy applications [18]. Excellent electrocatalytic properties of transformed hair (pyrolyzed) reveal that it could be used as promising catalyst, $\mathrm{CO}_{2}$ adsorption, hydrogen storage and also in the supercapacitors.

\section{Characterization Techniques}

Several characterization technique such as; Scanning electron microscope (SEM), Transmission electron microscope (TEM), X-Ray Diffraction (XRD), Raman spectroscopy and XRay photoelectron spectroscopy (XPS), Fourier transform-infrared spectroscopy (FTIR) has been found on the pyrolyzed hair sample by the different researchers in order to study morphology, structure and the chemical composition.

\section{Chemical composition}

X-ray photoelectron spectroscopy (XPS) technique is used to probes the elemental composition of a material. XPS spectra are obtained by irradiating a material with a beam of energetic photons while measuring the kinetic energy and the number of electron that escape [31]. XPS spectrum of carbonized hair of $200{ }^{\circ} \mathrm{C}$ over $24 \mathrm{hrs}$. reveals three major peaks at about $284.6 \mathrm{eV}, 399.5 \mathrm{eV}$ and 531.0 $\mathrm{eV}$ that confirms presence of carbon (C), nitrogen $(\mathrm{N})$ and oxygen $(\mathrm{O})$, but at high resolution $\mathrm{C}$ and $\mathrm{O}$ XPS spectrum shows presence of $\mathrm{C}-\mathrm{C} / \mathrm{C}=\mathrm{C}, \mathrm{C}$ $\mathrm{N} / \mathrm{C}-\mathrm{O}$ and $\mathrm{C}=\mathrm{O}$ bonds, whereas high resolution of $\mathrm{N}$, XPS spectrum shows presence of pyridinic $\mathrm{N}$ and pyrrolic $\mathrm{N}$ as shown in figure 4(A) [24]. 
Quaternary or graphine $\mathrm{N}$ peak and sulphur (S) peak above the graphene $\mathrm{N}$ at $164 \mathrm{eV}$ can be seen in figure 4(B) [18]. Moreover, the content of carbon decreases with increase in temperature which was confirmed by energy-assisted X-ray spectroscopy (EDS) system based on SEM [32].
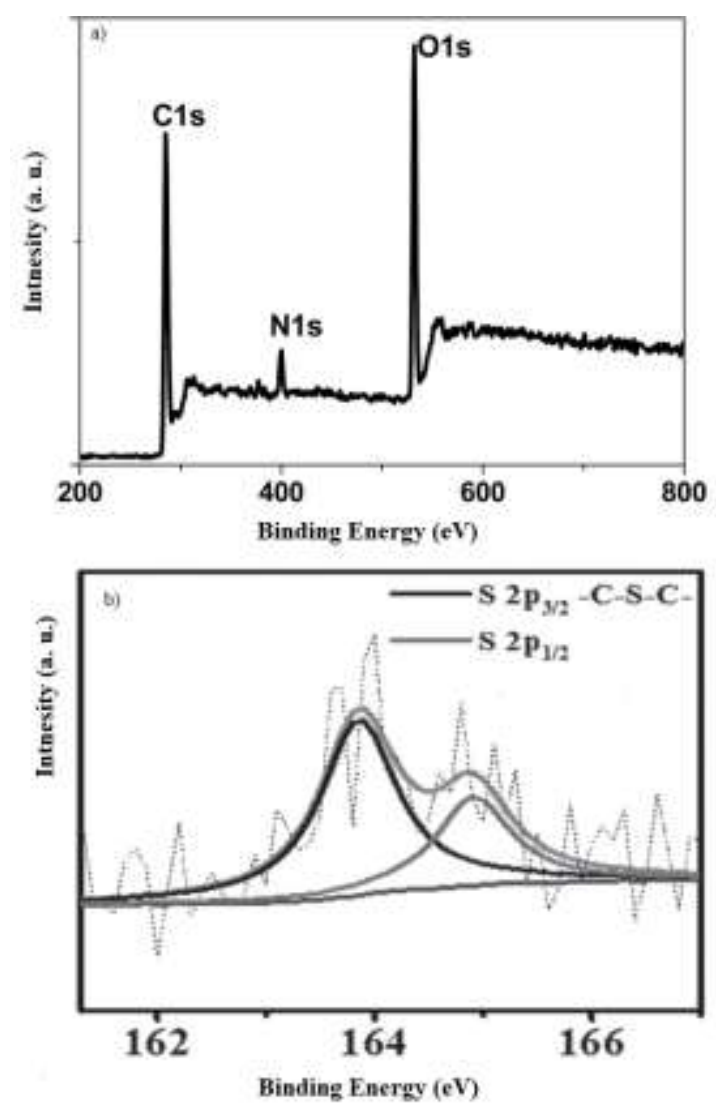

Fig. 4: XPS spectra of pyrolyzed hair showing the presence of oxygen, nitrogen and carbon (a) [24] and C-S-C type of sulphur (b) [18]

FTIR spectrum of human hair char shows the presence of various functional groups in pyrolyzed form. Absorption band at $2930 \mathrm{~cm}^{-1}, 1410 \mathrm{~cm}^{-1}$, and $1330 \mathrm{~cm}^{-1}$ associated with the vibration of $\mathrm{C}-\mathrm{H}$, $\mathrm{C}=\mathrm{C}$ and $\mathrm{C}-\mathrm{C}$ functional groups where broad band at $3300 \mathrm{~cm}^{-1}$ reveals the presence of $\mathrm{N}-\mathrm{H}$ and $\mathrm{O}-\mathrm{H}$ group respectively. The peak about $1690 \mathrm{~cm}^{-1}$ and $1515 \mathrm{~cm}^{-1}$ in FTIR spectrum conforms the bending vibration and stretching vibration of the $\mathrm{C}=\mathrm{O}$ and $\mathrm{N}-\mathrm{H}$ functional groups [24]. Further, additional peak corresponding to the $\mathrm{C}-\mathrm{N}$ groups of aliphatic and aromatic amines and $\mathrm{H}-\mathrm{O}-\mathrm{H}$ (bending band) were found at $1365-1370 \mathrm{~cm}^{-1}$ and $1600 \mathrm{~cm}^{-1}$ respectively [32] as shown in figure 5. This confirmed the presence of carboxylic, alkyl, aryl and amino functional groups in the pyrolyzed hair.

\section{Microscopic studies}

Scanning electron microscope (SEM) is used to study the morphological structure of the given sample. SEM micrograph of the pyrolyzed hair $\left(300{ }^{\circ} \mathrm{C}\right.$ and $800{ }^{\circ} \mathrm{C}$ ) shows the existence of the lamellar shaped carbon flakes. These arrangement is similar to the SEM image of the hair cuticle in figure 2, that means these structure were retain and unaltered during carbonization process [17] but porosity of the samples intensify with increase in temperature [32]. These carbon flakes are usually formed by randomly piled graphite like plane with high level of disorder, which consequence the high surface area and porosity which is shown in figure 6(A) [18].

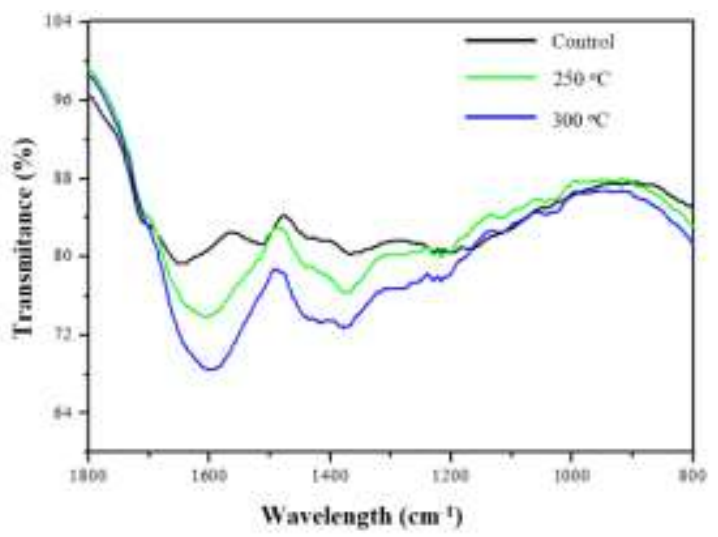

Fig. 5: FTIR spectra of carbonized hair samples prepared at different temperatures (activated by $\mathrm{ZnCl}_{2}$ ) showing presence of different functional group [32]

The pyrolyzed sample were further analyzed with transmission electron microscope (TEM), this technique is generally used to know the particle size and the internal structure. In TEM, a parallel beam of electrons is focused on to sample and allowed to penetrate through the sample. Some electrons are scattered and energy loss by 
inelastically scattered electron is recorded by TEM and displayed in micrograph [33]. TEM images of the hydrothermal treatment of human hair at $200{ }^{\circ} \mathrm{C}$ for 24 hours revealed the presence of quantum dots in well scattered manner having diameter and structure in nanoscale range $(2-10 \mathrm{~nm})$ which is shown in figure 6(B) [24]. However, TEM performed on the active carbon containing flakes graph shows thin pile of carbon sheets contain micro/meso-porous structure having channel like texture. These channels facilitate for penetration and the movement of the electrolytic ion in supercapacitors [17, 18].

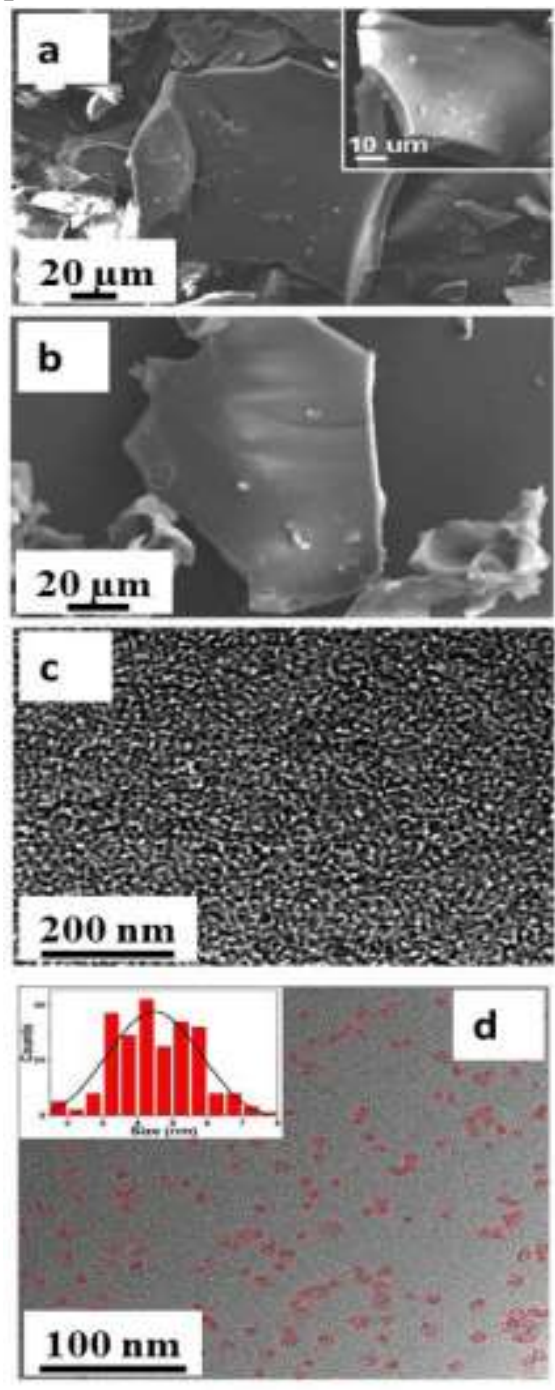

Fig. 6: SEM micrograph of hair carbonized at 300 ${ }^{\circ} \mathrm{C}$ (a) and $800{ }^{\circ} \mathrm{C}$ (b) [17], TEM image of hair carbonized at $800{ }^{\circ} \mathrm{C}$ (c) [17] and TEM image with size distribution of CQDs (d) [24]

\section{Optical characterization}

X-ray diffraction (XRD) of the pyrolyzed sample was used to know the crystal nature of sample. XRD graph is plotted with intensity versus $2 \theta$. Peaks were observed at about $22.3^{\circ}$ and $43.8^{\circ}$ on spectra of the material which show the graphite like structure, these graphitic stacks are responsible for electrical conductivity and nature of graph shows degree of the crystalline increase in temperature [17] but Altuntaş et. al reported the degree of crystalline decreases with increases in temperature [32]. It can be assumed that crystalline behavior depends on nature of treatments/activations of sample which can be seen in figure 7 .
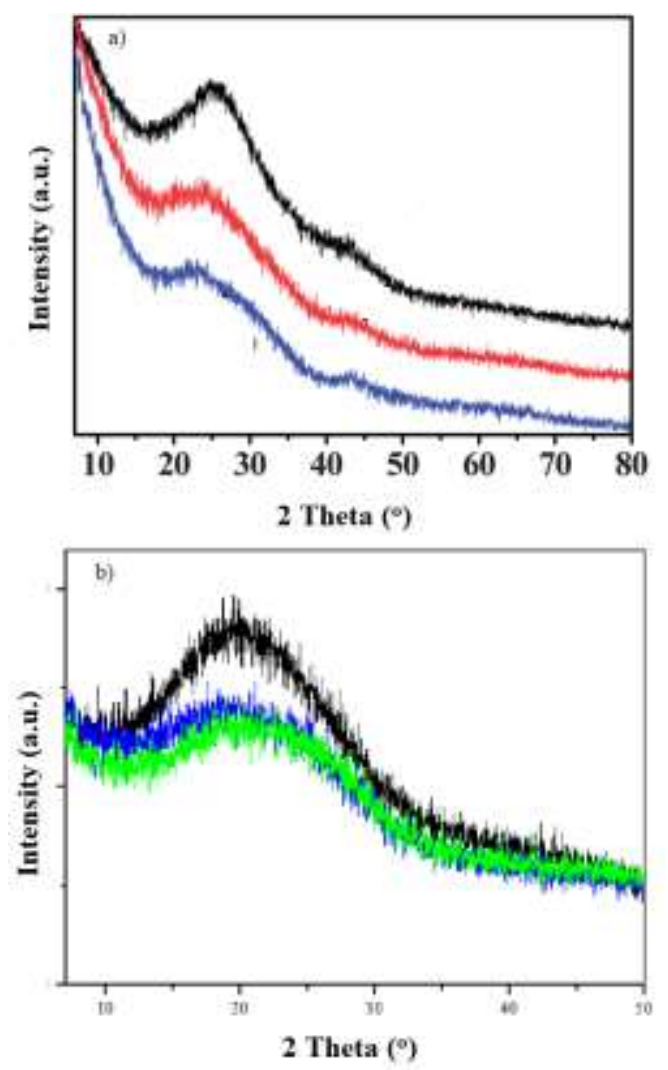

Fig. 7: XRD patterns showing crystalline nature of $\mathrm{KOH}$ activated (a) [17] and $\mathrm{ZnCl}_{2}$ activated (b) [32] pyrolyzed hair

Raman spectroscopy is a nondestructive, ambient probing instrument to characterize the detail bonding structure of carbon materials. Mostly structures are analyzed in context of diamond (D) band versus graphite $(\mathrm{G})$ band. For pure diamond a 
Raman active mode appear at $1332 \mathrm{~cm}^{-1}$ and for graphite active line appear at $1575 \mathrm{~cm}^{-1}$ [33]. Crystal structure can also be studied through diffraction pattern using Raman spectroscopy. The graphite like structure was determined by ratio of defects (D) to graphitic $(\mathrm{G})$ bands of the sample i.e. $\mathrm{D} / \mathrm{G}$ ratio. In figure 8 peaks were found around $1320 \mathrm{~cm}^{-1}$ and $1590 \mathrm{~cm}^{-1}$ in Raman spectra that represents diamond and the graphitic band respectively. $\mathrm{D} / \mathrm{G}$ ratio decreases with the increase in the temperature which means deformation decreases with carbonization temperature [17,18], similar result was reported by Altuntaş et. al [32]

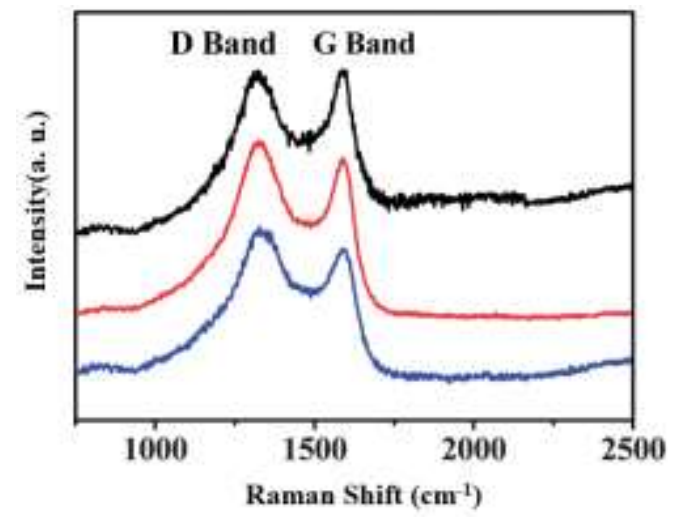

Fig. 8: Raman spectra of the carbon materials obtained from hair showing D and G bands [17]

\section{Conclusions}

Hair a keratinized filament has very strong crosslinked disulphide linkage and covered by thick cuticle. These two disulphide linkage and cuticle is responsible for the toughness of the hair. Microstructure is different in Asian, African and Caucasian hair. Hair on low temperature pyrolysis yields a black shiny char. This char on spectroscopic analysis shows the presence of carboxylic, alkyl, aryl and amino functional groups and also contains hetero atom like $\mathrm{N}, \mathrm{S}$ and $\mathrm{O}$. However, XRD shows degree of crystalline nature may found to be in reverse order under different treatment condition with increase in temperature. Electron microscopic analysis shows the presence of randomly oriented flakes like structure having nanoscale dimension. These nanostructures have channels like texture, high surface area and porosity..

These property of the pyrolyzed sample helps to enhance the electrochemical properties. The channels intensify the movements of electrolyte in supercapacitor so acts as an electrode. As better my knowledge no any systematic study of the biomedical application has been reported yet though its uses was reported in the $16^{\text {th }}$ century as a biomedicine. It may have many significant hidden scientific properties. Investigations of such properties in the pyrolyzed hair contribute to the science for better innovation. Commercialization of the use of pyrolyzed hair may help to control waste produced by the hair fibers.

\section{References}

[1] B. Bhushan, Biophysics of the human hair: structural, nanomechanical, and nanotribological studeies, Springer, Berlin (2010) 1-50

[2] J.R Rouse, M.E.V. Dyke, A Review of the KeratinBased Biomaterials for Biomedical Application, Materials 3 (2010) 999-1014, http://doi.ord/10.3390/ma3020999

[3] J. Schweizer, P.E. Bowden, P.A. Coulombe, L. Langbein, E. B. Lane, T. M. Magin, L. Maltais, M. B. Omary, D. A. Parry, M. A. Rogers, M. W. Wright, New consensus nomenclature for mammalian keratins, The Journal of Cell Biology. 174 (2006) 169 -174. http://doi.org/ 10.1083/jcb.200603161

[4] M.A. Rogers, L. Langbein, S. Praetzel-Wunder, H. Winter, J. Schweizer. Human hair keratinassociated proteins (KAPs), International Review of Cytology. $251 \quad$ (2006) 209-263. http://doi.org/10.1016/S0074-7696(06)51006-X

[5] G. Wei, B. Bhushan, P.M. Togerson. Nanomechanical characterization of human hair using nanoindention and SEM. Ultramicroscopy. 105 (2005) 248-266. http://doi.org/10.1016/j.ultramic.2005.06.033

[6] C.R. Robbin. Chemical and physical behavior of human hair. Springer, New York. (2012) 39-68. http://doi.org/10.1007/978-1-4757-2009-9

[7] M. Brehu, I. Spiridon. Thermal degradation of keratin waste, Journal of Analytical and Applied Pyrolysis. 91 (2011) 288-295. http://doi.org/10.1016/j.jaap.2011.03.003 
[8] A. Gupta. Human hair waste and it's utilization: gaps and possibilities, Journal of Waste Management. $2014 \quad$ (2014) 1-17. http://doi.org/10.1155/2014/498018

[9] V. Verma, P. Verma, P. Ray, A.R. Ray, Preparation of scaffolds from human hair proteins for tissue-engineering applications, Biomedical Materials. 3 (2008) 1-13. http://doi.org/10.1088/1748-6041/3/2/025007

[10] D.E. Rivett, S.W. Ward, L.M. Belkin, J.A.M. Ramshaw, J.F.K. Wilshare. Keratin and Wool Research. In The Lennox Legancy; CSIRO Publishing; Collingwood, VIC, Australia. (1996) 1

[11] L.S. Zhen. Ben Cao Gang Mu; The Time Literature \& Art Press: Changchun, Jilin, China, (2005).

[12] D. Savova, E. Apak, E. Ekinci, F. Yardim, N. Petrov, T. Budinova, M. Razvigorova, V. Minkova, Biomass conversion to carbon adsorbents and gas. Biomass and Bioenergy. 21 (2001) 133-142. http://doi.org/10.1016/S0961-9534(01)00027-7

[13] D.L. Klass. Biomass of renewable energy, fuels and chemicals. San Diego, CA: Academic Press; (1998) Ch. 8: Thermal Conversion: Pyrolysis and Liquefaction, pp. 225-268. ISBN: 9780124109506

[14] F. Saurez-Garcia, A. Martiniz-Alonsoa, J.M.D. Tascon. Pyrolysis of apple pulp: effect of operation conditions and chemical additives, Journal of Analytical \& Applied Pyrolysis. 62 (2002) 93-109. http://doi.org/10.1016/S0165-2370(00)00216-3.

[15] Y. Yorgun, S. Sensoz, O.M. Kockar. Flash pyrolysis of sunflower oil cake for production of liquid fuels, Journal of Analytical and Applied Pyrolysis. $\quad 60 \quad$ (2001) 1-12. http://doi.org/10.1016/S0165-2370(00)00102-9.

[16] D. Meier, O. Faix. State of the art of applied fast pyrolysis of lignocellulosic materials-a review, Biosource Technology, 68 (1999) 71-77. http://doi.org/10.1016/S0960-8524(98)00086-8

[17] W. Qian, F. Sun, Y. Xu, L. Qiu, C. Liu, S. Wang, F. Yan. Human hair-derived carbon flakes for electrochemical supercapacitors, Energy and Environmental, Science. 7 (2014) 379-386. http://doi.org/10.1039/C3EE43111H

[18] K.N. Chaudhari, Y.M. Song, J.S. Yu, . Transforming hair into heteroatom-doped carbon with high surface area, Small. 10 (2014) 26252636. http://doi.org/10.1002/smll.201303831

[19] D.H. Shaikh, H.Z. Shaikh. Ash as a unique natural medicine for wound healing, J. ISRA Medical. 1 (2009) 72-78.
[20] W.F. Wood. Anesthesia of Honeybees by Smoke From Pyrolysis of Puffballs and Keratin, Journal of Apicultural Research. 22 (2015) 107-110. http://doi.org/10.1080/00218839.1983.11100569

[21] P. Oudhia. Revised version of selected Botanical.com articles. Part 2,(2010) http://pankajoudhia.com/.

[22] H. Lijie. Stresses on tresses. The Straits Times. C5 (2014).

http://www.gajahgallery.com/exhibitions/Press/ij7f 9roj60tryzdj1d7f.pdf; retrieved: Dec. 30, 2019

[23] C.P. Poole, F.J. Owens. Introduction to Nanotechnology. Wiley-Interscience, New York, (2003). ISBN: 978-0-471-07935-4

[24] Y. Guo, L. Zhang, F. Cao, Y. Leng. Thermal treatment of hair for the synthesis of sustainable carbon quantum dots and the applications for sensing $\mathrm{Hg}^{2+}$, Scientific Reports. 6 (2016) 35795. http://doi.org/10.1038/srep35795(2016)

[25] C. Beyers. The keratin or horny substance of the hair. German pat. DE22643, 14 October ( 1907).

[26] T.C. Tan, C.K. Chia, C.K. Teo. Uptake of metal ions by chemically treated human hair, Water Research. 19 (1985) 157-162. http://doi.org/10.1016/0043-1354(85)90193-9

[27] M. Winter, R.J. Brodd. What are batteries, fuel cells, and supercapacitors? Chemical Reviews. $104 \quad$ (2004) 4245-4270. http://doi.org/10.1021/cr020730k

[28] S. Giddey, S.P.S. Badwal, A. Kulkarni, C. Munnings, Progress in Energy and Combustion Science.38 (2012) 360-399. http://doi.org/10.1016/j.pecs.2012.01.003

[29] A. Morozan, B. Jousselme, S. Palacin. Energy and Environmental Science. 4 (2011) 1238-1254. http://doi.org/10.1039/C0EE00601G

[30] B. S. Kondawar. Conducting polymer nanocomposites for supercapacitors. Smithers Rapha, Shawbury, UK. (2015).

[31] T. Susi, P. Ayala. Doping carbon nanomaterials with heteroatoms. Carbon Nanomaterials for Advanced Energy Systems., John Weily and Sons, (2015) 133-161. https://doi.org/10.1002/9781118980989.ch4

[32] D. B. Altuntaş, V. Nevruzoglu, M. Dokumaci, S. Cam. Synthesis and characterization of activated carbon produced from waste human hair mass using chemical activation, Carbon Letters. 30 (2019) 301-313. http://doi.org/10.1007/s42823-019-00099-9

[33] P. K. Chu, L. Li. Characterization of amorphous and nanocrystalline carbon films, Materials Chemistry and Physics.96(2006)253-277. http://doi.org/10.1016/j.matchemphys.2005.07.048 